\section{Review: intensive glucose control reduced some CV events but did not change mortality in type 2 diabetes}

\section{QUESTION}

Does intensive glucose control reduce cardiovascular (CV) events and mortality in patients with type 2 diabetes mellitus?

\section{REVIEW SCOPE}

Included studies compared intensive glucose-lowering regimens with standard regimens (placebo, standard care, or reduced-intensity control) in stable patients with type 2 diabetes mellitus, had significant group differences in haemoglobin $\mathrm{A}_{1 \mathrm{c}}\left(\mathrm{HbA}_{1 \mathrm{c}}\right)$ concentrations during follow-up, reported $\mathrm{CV}$ events as primary outcomes, and provided adequate data for outcomes of interest: non-fatal myocardial infarction $(\mathrm{MI})$, coronary heart disease (CHD), stroke, and all-cause mortality. Other outcomes included $\mathrm{HbA}_{1 \mathrm{c}}$ concentrations, heart failure (HF), hypoglycaemia, and weight gain.

\section{REVIEW METHODS}

Medline, EMBASE/Excerpta Medica, and Cochrane Central (all 1970 to Jan 2009) and reference lists were searched for randomised controlled trials (RCTs). Experts were contacted. 5 RCTs ( $n=33$ 040, mean age $62 \mathrm{y}, 62 \%$ men) met the selection criteria. Intensive glucose control regimens varied.

\section{MAIN RESULTS}

The main results are in the table. Mean $\mathrm{HbA}_{1 \mathrm{c}}$ concentration at baseline was $7.8 \%$ (range $7.1-9.4 \%$ ). At a mean 5 years of follow-up, intensive glucose control reduced $\mathrm{HbA}_{1 \mathrm{c}}$ concentrations more than standard control (mean 6.6\% v 7.5\%, difference $0.9 \%, 95 \%$ CI 0.88 to 0.92 ). Intensive glucose control was associated with more frequent serious hypoglycaemic events than standard control (mean $2.3 \% v 1.2 \%$, p value not reported) and increased weight gain (mean $2.4 \mathrm{v}$ $-0.1 \mathrm{~kg}, \mathrm{p}$ value not reported).

\section{CONCLUSION}

In patients with type 2 diabetes mellitus, intensive glucose control reduced some cardiovascular events but did not change overall mortality.

Abstract and commentary also appear in ACP Journal Club.

\section{ABSTRACTED FROM}

Ray KK, Seshasai SR, Wijesuriya S, et al. Effect of intensive control of glucose on cardiovascular outcomes and death in patients with diabetes mellitus: a meta-analysis of randomised controlled trials. Lancet 2009;373:1765-72.

Correspondence to: Dr K K Ray, Strangeways Research Laboratory, Cambridge, UK; kkr25@medschl.cam.ac.uk

Source of funding: no external funding.

- Clinical Impact Ratings: IM/Ambulatory care 6/7; Cardiology 6/7; GP/FP/Primary care 5/7; Endocrine 5/7; Nephrology 5/7; Neurology $5 / 7$

Intensive $v$ standard glucose control in type 2 diabetes*

\begin{tabular}{|c|c|c|c|c|}
\hline \multirow[b]{2}{*}{ Outcomes } & \multicolumn{2}{|c|}{ Weighted event rates } & \multicolumn{2}{|c|}{ At 2.9 to 10.1 years } \\
\hline & Intensive & Standard & RRR (95\% CI) & NNT (CI) \\
\hline Non-fatal MI & $4.0 \%$ & $4.8 \%$ & $16 \%$ (6 to 25$)$ & 131 (84 to 349 ) \\
\hline CHD & $6.1 \%$ & $7.2 \%$ & $15 \%(9$ to 20$)$ & 93 (70 to 155$)$ \\
\hline \multirow[t]{2}{*}{ Stroke } & $3.1 \%$ & $3.4 \%$ & $10 \%(-1$ to 20$)$ & Not significant \\
\hline & & & RRI (CI) & NNH (CI) \\
\hline Mortality & $8.5 \%$ & $8.4 \%$ & $2 \%(-12$ to 19$) \dagger$ & Not significant \\
\hline Heart failure & $4.4 \%$ & $4.1 \%$ & $8 \%(-10$ to 29$) \dagger$ & Not significant \\
\hline
\end{tabular}

${ }^{*} \mathrm{CHD}$, coronary heart disease; MI, myocardial infarction; other abbreviations defined in glossary. All results based on 5 trials ( $n=33$ 040). RRR, RRI, NNT, NNH, and Cl calculated from data in article using a random-effects model.

$\uparrow$ Results were heterogeneous.

$\mathrm{U}$ ntil now, glucose control had not been convincingly shown to reduce CV events in type 2 diabetes. Although the meta-analysis by Ray et al showed a benefit of intensive glycaemic control for non-fatal Mls and CHD, some caveats merit mention.

First, few significant effects were found in individual studies despite adequate power. This suggests that any benefits of glycaemic control for macrovascular outcomes are probably modest. Indeed, one would need to treat 131 patients over 5 years with intensive glycaemic control to prevent 1 non-fatal MI. In contrast, blood pressure control and statin therapy have been shown to reduce both CV events and mortality at 5 years, with numbers needed to treat of 8 to 30 with blood pressure control $^{1}$ and 23 with statins. ${ }^{2}$

Second, reductions in non-fatal Mls and CHD did not translate into reduced mortality. Glycaemic control may have both positive and negative effects on overall CV risk, depending on methods and intensity of control. In the ACCORD trial, ${ }^{3}$ an aggressive approach to rapidly lowering $\mathrm{HbA}_{1 \mathrm{c}}$ to $6 \%$ increased mortality, suggesting that such lowering to below the recommended threshold of $7 \%$ may cause more harm than good, possibly through increased hypoglycaemia. Ray et al also found heterogeneity for HF outcomes; higher risks were associated with glitazone-based regimens, suggesting that the CV risk-benefit ratio may depend on the medications used.

This meta-analysis provides support for modest benefits of glycaemic control for some macrovascular events in patients with type 2 diabetes. The benefit and safety of $\mathrm{HbA}_{1 \mathrm{c}}$ targets below the recommended $7 \%$ is uncertain and may depend on the population and regimen used. Moreover, effects of glucose control may vary with different therapeutic approaches. Benefits of glycaemic control for CHD events and microvascular disease must be viewed alongside the potential risks of hypoglycaemia and of HF if glitazones are used.

\section{Lorraine L Lipscombe, MD, MSc, FRCPC}

Women's College Hospital, University of Toronto Toronto, Ontario, Canada

1. Norris SL, Kansagara D, Bougatsos C, et al. Screening adults for type 2 diabetes: a review of the evidence for the US Preventive Services Task Force. Ann Intern Med 2008;148:855-68.

2. Cholesterol Treatment Trialists' (CTT) Collaborators, Kearney PM, Blackwell L, et al. Efficacy of cholesterol-lowering therapy in 18,686 people with diabetes in 14 randomised trials of statins: a meta-analysis. Lancet 2008;371:117-25.

3. Action to Control Cardiovascular Risk in Diabetes Study Group, Gerstein HC, Miller ME, et al. Effects of intensive glucose lowering in type 2 diabetes. $N$ Engl $J$ Med 2008;358:2545-59. 